\title{
The effect of immersion with time and water variations on bending strength of malapoga wood (Toona Ciliata M. Roem)
}

\author{
Awal Syahrani Sirajuddin ${ }^{1 *}$, Alimuddin $\operatorname{Sam}^{1}$ and Basri ${ }^{1}$ \\ ${ }^{1}$ Mechanical Engineering, Tadulako University, 94118 Palu, Indonesia
}

\begin{abstract}
Bending strength is a parameter used in wood structure planning. The purpose of this study was to determine the effect of time and water of immersion on increasing bending strength. The main ingredient of this research is malapoga wood (Toona Ciliata $\mathrm{M}$. Roem) which was previously preserved by immersion with brackish water, sea water and river for 2,4,6 and 8 weeks. Bending strength specimen and testing procedure refer to ASTM D14. A cross section of the test specimen is then subjected to a macro photograph to determine its failure mechanism. The test results show that Immersion using river water gives a greater bending strength value followed by using brackish water and sea water. The maximum bending strength of the river water is $26.64 \mathrm{MPa}$ at the time of immersion 4 weeks later followed by brackish water at $25.86 \mathrm{MPa}$ while the maximum bending strength value of seawater occurs in immersion for 6 weeks which is $24.52 \mathrm{MPa}$. The immersion time causes the malapoga wood to become denser due to all the cavities in the malapoga wood filled with material contained in brackish water, sea and river so that the fibers of malapoga wood close up, dry out and crystallize inside the malapoga wood cavity which causes the bending strength of malapoga to increase.
\end{abstract}

\section{Introduction}

Wood is one of the oldest natural building materials in the world. A number of desirable factors, such as ease of fabrication, thermal insulation, and environmental compatibility have made wood one of the most popular construction materials. On the other hand, wood is a material that is difficult to analyze compared to steel or concrete because it is orthotropic [1] influenced by its fibers, causing different mechanical properties in relation to the three axes perpendicular to each other; longitudinal, radial and tangential axes.

In the area of Central Sulawesi, there is community wood that is still less known by the community in general, this Central Sulawesi people's wood is called Malapoga wood (Toona Ciliata M. Roo). We can find this community wood in Parigi Moutong, Poso, Napu, Palolo, and Morowali areas. Besides being easily obtained, Malapoga wood is classified as lightweight but strong wood, and is cheaper compared to teak, resin and ebony according to

\footnotetext{
${ }^{*}$ Corresponding author : awsyahrani untad@yahoo.com
} 
public information. The availability of community timber is expected to be used optimally to reduce deforestation as a source of wood suppliers.

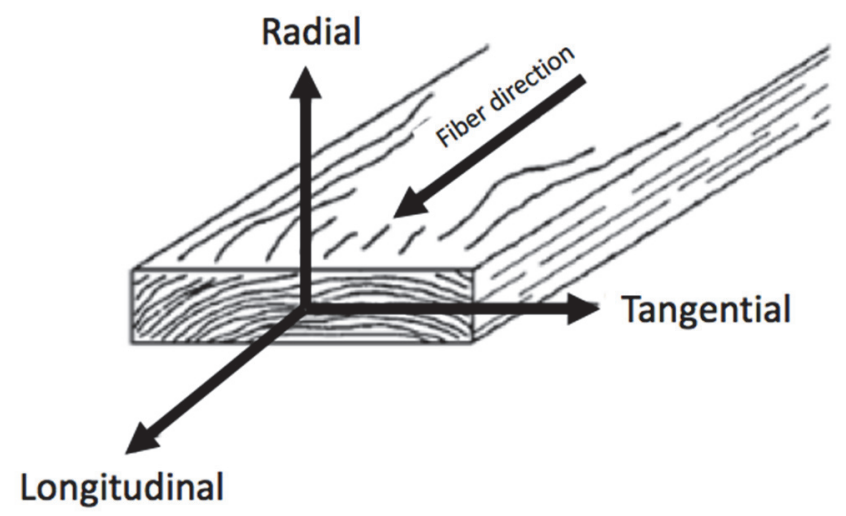

Fig. 1. Classification of beam bending failure [2]

Data sources from other parties about the bending strength of malapoga wood are still difficult to find in certain institutions. Therefore, this research was conducted to complement the data about the bending strength of malapoga wood and also to determine the effect of time and water of immersion on increasing bending strength.

\subsection{Failure Mode}

Bending produces a longitudinal stress and compression pressure which is distributed at the depth of the cross section. This stress causes brittle failure due to rupture of wood fibers.

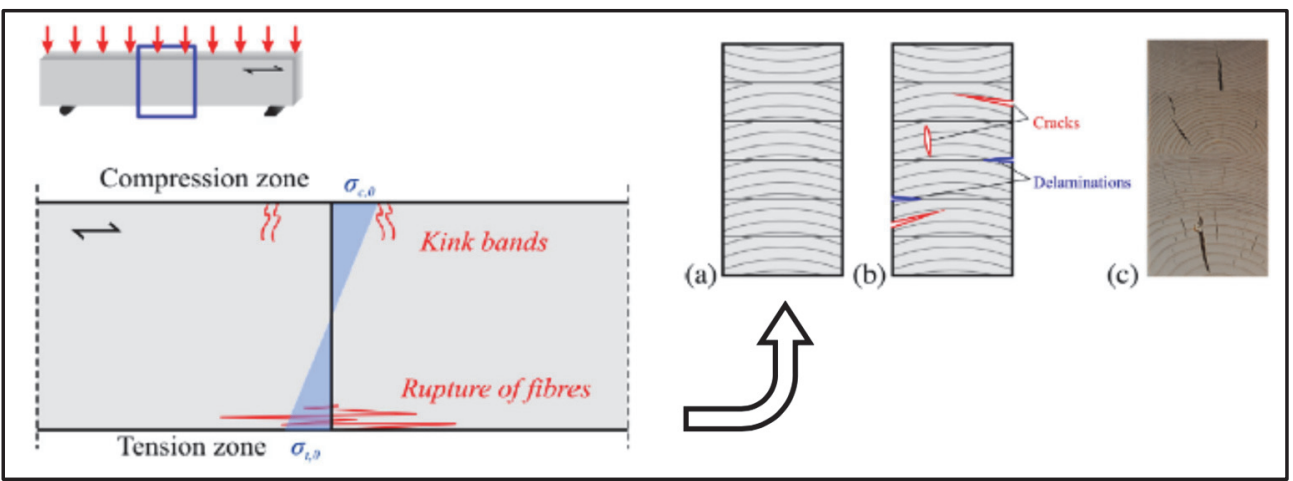

Fig. 2. Images for bending failures and cross sections of wood; (a) sketch of undamaged views, (b) cross-section sketch with some damage such as cracks and delamination, (c) real examples of cross sections that have been damaged [3]

Longitudinal compression stress produces elastic and plastic deformation that can be described as a ductile material and leads to kink bands or called kink bands. The most common type of failure is observed as the appearance of cracks in the direction of the fiber. Based on ASTM D143 [4] there are various types of static bending flexural failures with the center pint loading test object model. Beam failure classifications are: simple tension, crossgrain tension, brash tension and compression [4]. 
What is meant by wood density is the ratio between wood mass or the ratio between wood density and the amount of water contained in wood. According to [6] the heavier the wood, the stronger the wood. The lighter the type of wood, the less there is strength in the wood.

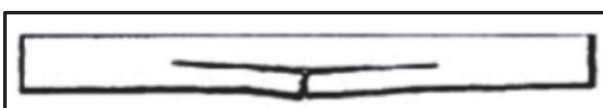

(a) Simple Tension

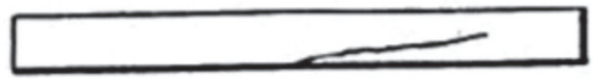

(b) Cross-grain Tension

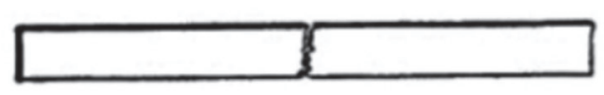

(c) Brash Tension

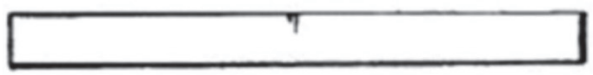

(d) Compression

Fig. 3. Classification of beam bending failure [4]

\subsection{Malapoga Timber (Toona Ciliata M. Roem)}

Malapoga wood has characteristics such as stems that are straight, classified as large and medium, the height can reach up to $20-30 \mathrm{~cm}$ and the diameter of the stem can reach $100 \mathrm{~cm}$, the color of the bark is dark gray or reddish brown, has a surface of the bark that is smooth and release the aroma when cut.
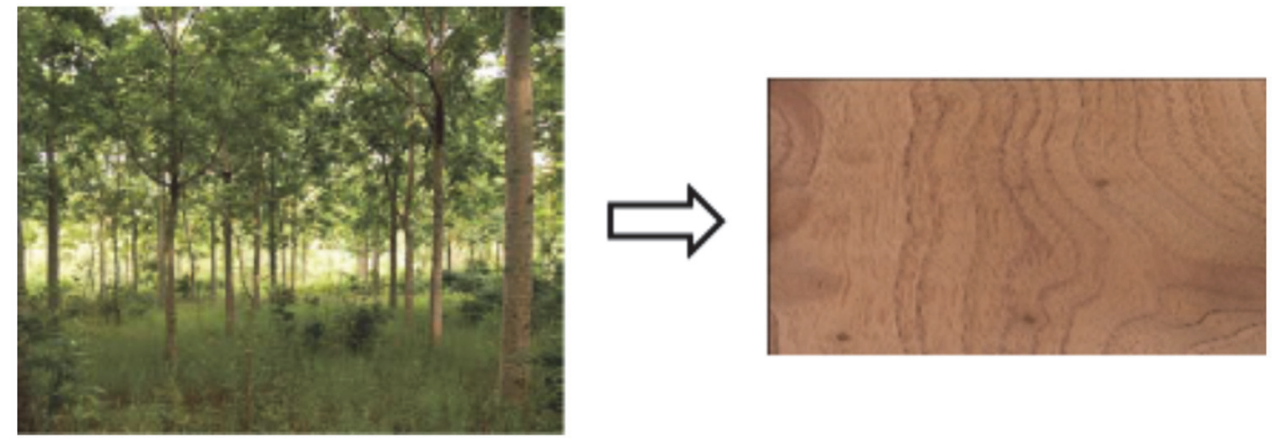

Fig. 4. Malapoga wood (Toona Ciliata M. Roem)

\section{Material and Methods}

The material used in this study is malapoga wood and using water of immersion, namely brackish water, sea water and river water. Malapoga wood is formed according to ASTM D143 standard with primary test specimens measuring $50 \mathrm{~mm} \times 50 \mathrm{~mm}$ and length $760 \mathrm{~mm}$ or using secondary specimen specimens with secondary methods measuring $25 \mathrm{~mm}$ x $25 \mathrm{~mm}$ and $410 \mathrm{~mm}$ long. Wood that has been formed is carried out followed by each immersion process using brackish water, sea water and river water with immersion time of 2, 4, 6 and 8 weeks. After going through the immersion process, the next step is drying using an oven until it reaches a water content of $12 \%$, then the malapoga wood is ready for the flexural testing process. Curved testing using the midpoint loading test method refers to the ASTM D143 standard with a loading speed of $2.5 \mathrm{~mm} / \mathrm{min}$ as shown in Figure 5. The cross section of the test specimen is then subjected to a macro photograph to determine the failure mechanism. 

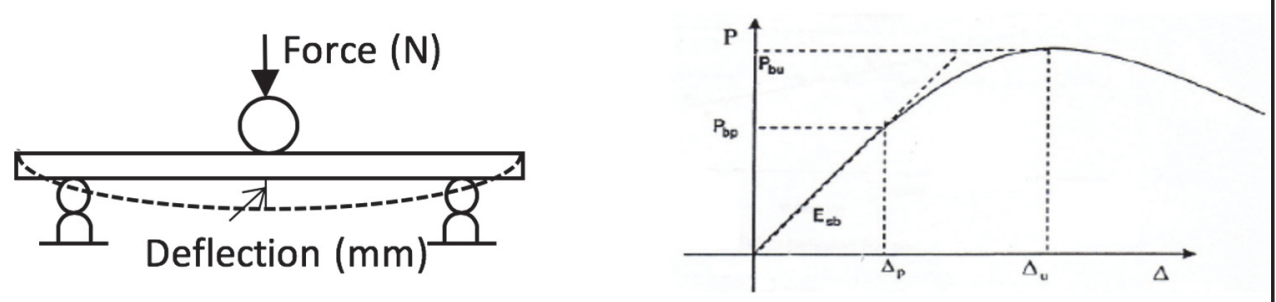

Fig. 5. Schematic test of bending strength and load-deflection curves

Moments that occur in wood specimens can be calculated by the equation (1):

$$
M=\frac{P}{2} \times \frac{L}{2}
$$

So, the bending strength can be formulated as follows equation (2) and equation (3)

Where:

$$
\sigma=\frac{M . Y}{I}
$$

$$
Y=\frac{d}{2}, I=\frac{b d^{3}}{12} \text { and, } \sigma_{b=}=\frac{3 \cdot P \cdot L}{2 \cdot b \cdot d^{2}}
$$

Meanwhile, to find the bending elastic modulus using the following formula equation (4):

$$
E_{b}=\frac{L^{3} P}{4 b d^{3} \cdot \delta}
$$

Where $\mathrm{P}=$ the load given $(\mathrm{N}) ; \mathrm{L}=$ Distance between the fulcrum $(\mathrm{mm}) ; \mathrm{b}$ and $\mathrm{d}$ are the width and thickness of the specimen $(\mathrm{mm}) ; \delta=\operatorname{deflection}(\mathrm{mm}) ; \mathrm{E} \_\mathrm{b}=$ modulus of elasticity $(\mathrm{MPa}) ; \sigma \_\mathrm{b}=$ bending strength (MPa); $\mathrm{M}=$ bending moment (MPa).

\section{Result and Discussion}

The mechanical properties of wood are a measure of the ability of wood to resist external forces. Static bending strength test is carried out to measure the strength of wood in all wood fibers subjected to the load slowly to see the effect of water of immersion, namely brackish water, sea water and river water with a long time of immersion for $2,4,6$, and 8 weeks on the strength malapoga wood bending. The bending strength test is based on ASTM D143 standards. The loading of the test is carried out until the specimen can no longer withstand the load given, so that there is a break in the test specimen and a maximum bending can be obtained by the specimen. Through bending strength testing obtained load-deflection relationship curves for each research variable.

Load-deflection curves show the effect of loading on deflection on malapoga wood. Deflection will increase along with the increasing amount of test load and will experience failure or breakage, when the maximum test load or when the wood is not able to hold the test load anymore. The test result data shows the difference in the value of bending strength obtained is influenced by the time of immersion and the type water of immersion. Malapoga wood bending strength value can be seen in Table 1 .

The malapoga wood which is processed with 2 weeks immersion using brackish water experiences a broken process at a maximum load of $1615 \mathrm{~N}$ with the resulting deflection of $12.5 \mathrm{~mm}$ so that the bending strength value is $23.26 \mathrm{MPa}$ and the modulus of elasticity is 279.07 MPa. The value of bending strength for each immersion water over the length of immersion time is shown in Figure 7. 


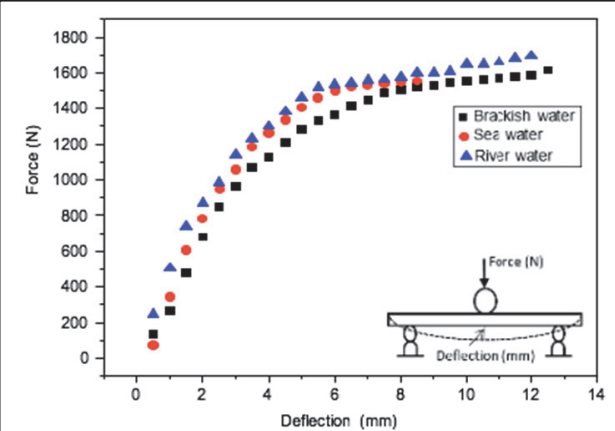

(a)

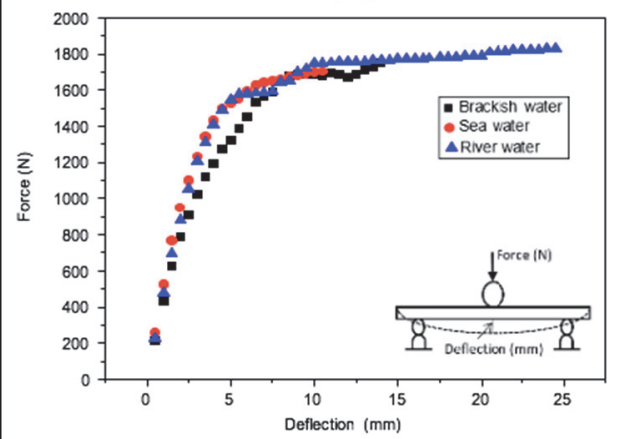

(c)

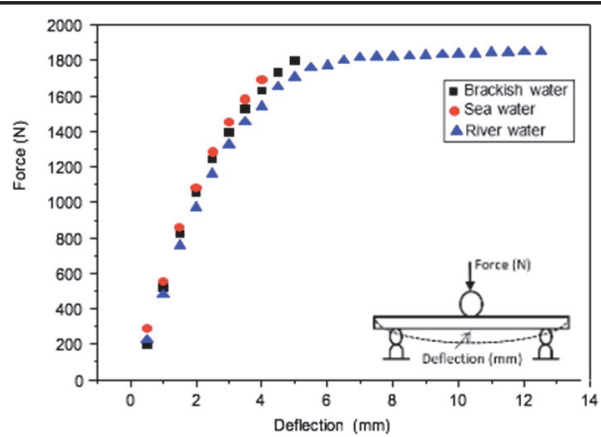

(b)

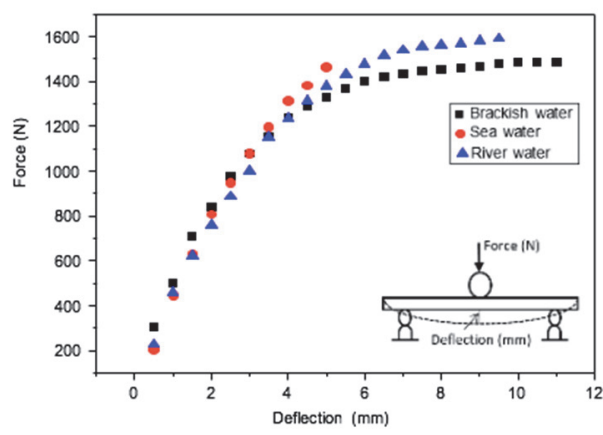

(d)

Fig. 6. Load curve - deflection; (a) 2 weeks immersion, (b) 4 weeks immersion, (c) 6 weeks immersion, (d) 8 weeks immersion

Table 1. Data on the results of malapoga wood bending strength tests

\begin{tabular}{|c|c|c|c|c|c|}
\hline \multicolumn{6}{|c|}{ Brackish water } \\
\hline $\begin{array}{c}\text { Time of } \\
\text { Immersion } \\
\text { (week) }\end{array}$ & $\begin{array}{c}\Delta \mathrm{L} \\
\mathrm{mm}\end{array}$ & $\begin{array}{c}\mathbf{F} \\
(\mathbf{k N})\end{array}$ & $\begin{array}{c}\text { Force } \\
(\mathbf{N})\end{array}$ & $\begin{array}{c}\sigma b \\
(\mathrm{MPa})\end{array}$ & $\begin{array}{c}\mathbf{E}_{\mathbf{b}} \\
(\mathbf{M p a})\end{array}$ \\
\hline 2 & 12.5 & 1.615 & 1615 & 23.26 & 279.07 \\
\hline 4 & 5 & 1.796 & 1796 & 25.86 & 775.87 \\
\hline 6 & 14 & 1.75 & 1750 & 25.20 & 270.00 \\
\hline 8 & 11 & 1.486 & 1486 & 21.40 & 291.80 \\
\hline \multicolumn{6}{|c|}{ Sea water } \\
\hline $\begin{array}{c}\text { Time of } \\
\text { Immersion } \\
\text { (week) }\end{array}$ & $\begin{array}{c}\Delta \mathrm{L} \\
\mathrm{mm}\end{array}$ & $\begin{array}{c}\mathbf{F} \\
(\mathbf{k N})\end{array}$ & $\begin{array}{c}\text { Force } \\
\text { (N) }\end{array}$ & $\begin{array}{c}\sigma_{b} \\
(\mathrm{MPa})\end{array}$ & $\begin{array}{c}\mathbf{E}_{\mathbf{b}} \\
\text { (Mpa) }\end{array}$ \\
\hline 2 & 8.5 & 1.555 & 1555 & 22.39 & 395.15 \\
\hline 4 & 4 & 1.692 & 1692 & 24.36 & 913.68 \\
\hline 6 & 10.5 & 1.702 & 1702 & 24.52 & 350.23 \\
\hline 8 & 5 & 1.462 & 1462 & 21.05 & 631.58 \\
\hline \multicolumn{6}{|c|}{ River water } \\
\hline $\begin{array}{c}\text { Time of } \\
\text { Immersion } \\
\text { (week) }\end{array}$ & $\begin{array}{c}\Delta \mathrm{L} \\
\mathrm{mm}\end{array}$ & $\begin{array}{c}F \\
(\mathbf{k N})\end{array}$ & $\begin{array}{l}\text { Force } \\
\text { (N) }\end{array}$ & $\begin{array}{c}\sigma b \\
(\mathrm{MPa})\end{array}$ & $\begin{array}{c}\mathbf{E}_{\mathbf{b}} \\
(\mathbf{M p a})\end{array}$ \\
\hline 2 & 12 & 1.694 & 1694 & 24.39 & 304.92 \\
\hline
\end{tabular}




\begin{tabular}{|c|c|c|c|c|c|}
\hline 4 & 12.5 & 1.85 & 1850 & 26.64 & 319.68 \\
\hline 6 & 24.5 & 1.83 & 1830 & 26.35 & 161.34 \\
\hline 8 & 9.5 & 1.59 & 1590 & 22.90 & 361.52 \\
\hline
\end{tabular}

The value of bending strength for brackish water, sea water and river water will increase at the time of immersion 2 weeks to 4 weeks and will experience a decrease in bending strength with increasing immersion time of 4 weeks. Immersion using river water provides greater bending strength value, followed by brackish water and sea water. The maximum bending strength in river water is $26.64 \mathrm{MPa}$ at the time of immersion 4 weeks later followed by brackish water at $25.86 \mathrm{MPa}$ while the maximum bending strength value in seawater occurs at 6 weeks immersion at $24.52 \mathrm{MPa}$.

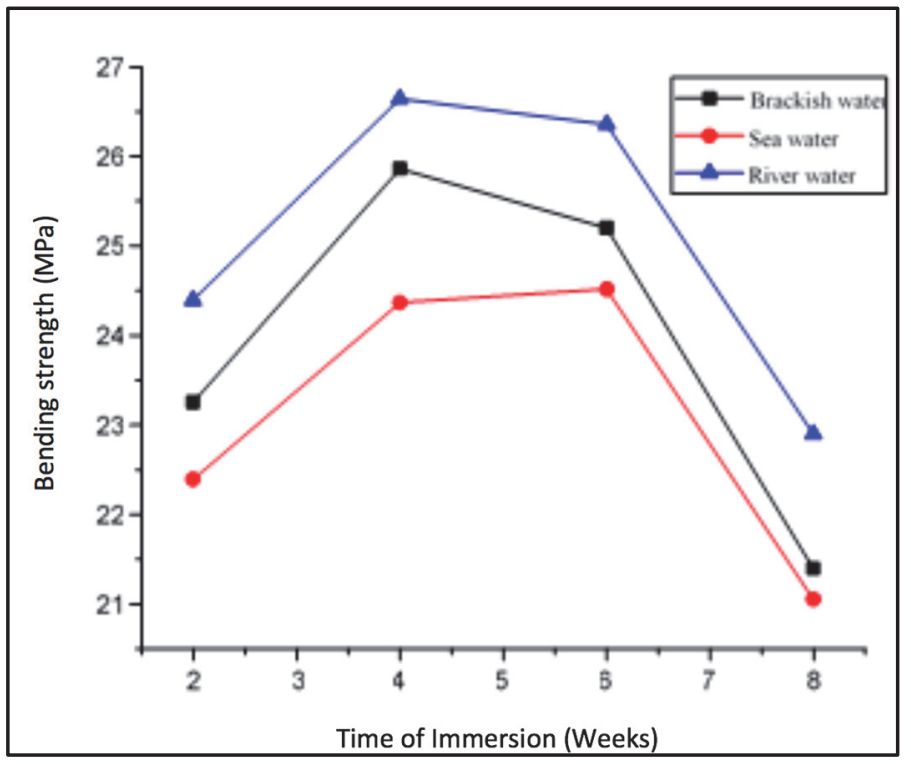

Fig. 7. Bending Strength vs. Time of Immersion

The modulus of elasticity fluctuates with increasing immersion time using brackish water, sea water and river water. This is because the value of the water content contained in the wood and the location of the cutting of the wood is different, because each part in the Malapoga log has different strengths, so it affects the modulus of elasticity of the malapoga wood. The modulus of elasticity value using sea water is higher, $913.68 \mathrm{MPa}$ at the time of immersion 4 weeks, then followed by brackish water at $775.87 \mathrm{MPa}$ and river water at 361.52 $\mathrm{MPa}$ at 8 weeks immersion. Another factor that causes an increase in the strength of wood is wood durability that is closely related to its use. Wood will last if it is able to withstand a variety of destructive factors so that it has a long service life, to withstand a variety of destructive factors, namely the preservation method, one of which is by immersing the wood using preservative media. Wood becomes durable because the preservative is poisonous. 


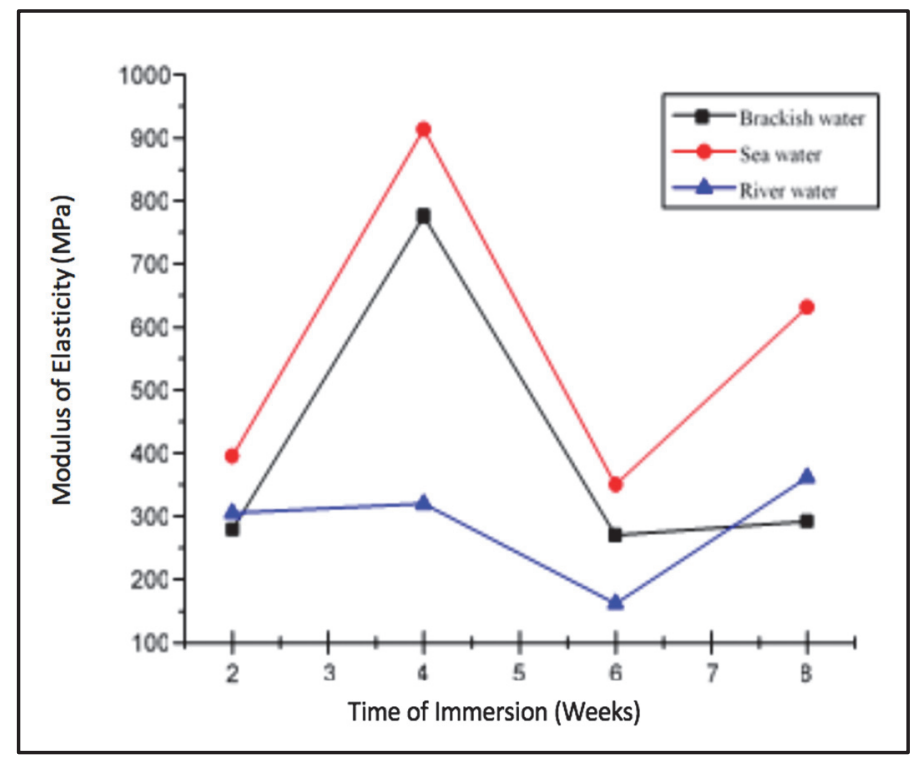

Fig. 8. Modulus of Elasticity vs. Immersion Time

The mechanical properties of wood are also affected by changes in water content below the fiber saturation point. This decrease in water content causes the cell wall to harden and be stiffened (Mardikanto 2011). The drier the wood, the higher the strength value of the wood. The immersion time causes the malapoga wood to become more dense which is caused by all the cavities in the malapoga wood filled with material contained in brackish water, sea water and river water so that during the heating process in the oven, the fibers of the malapoga wood close, dry and crystallize in the cavity malapoga wood which causes the bending strength value of malapoga wood has increased.

Figure 9 shows the failure of malapoga wood due to bending load using brackish water immersion. Immersion 2 and 4 weeks failed cross grain tension so that the appearance of cracks in the outer fibbers that spread across or across the direction of the fiber, this failure also occurs due to failure of pull on the fibber. Whereas for 6- weeks and 8-weeks immersion seems to experience compression failure so that it appears cracked on the part that has compressive force on wood.

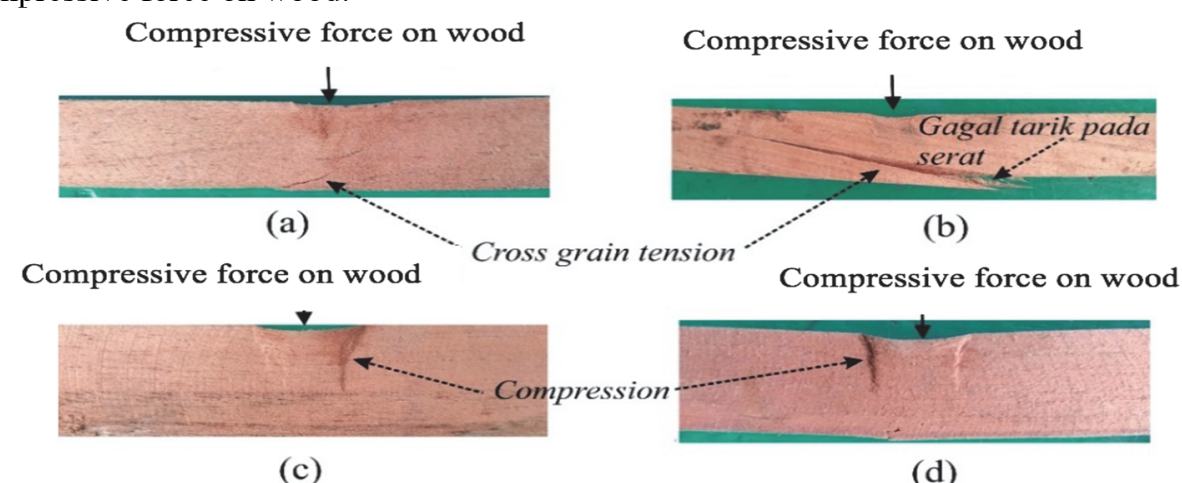

Fig. 9. Failure to bend the malapoga wood using brackish water; (a) 2 weeks, (b) 4 weeks, (c) 6 weeks, (d) 8 weeks 


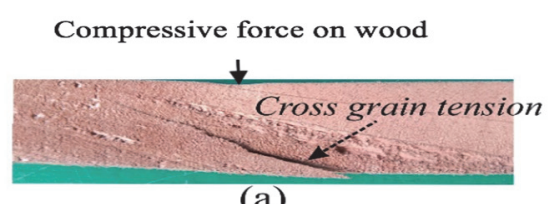

(a)

Compressive force on wood

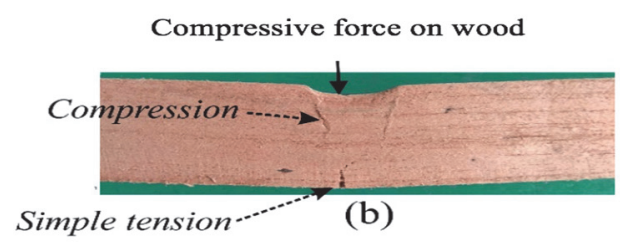

Compressive force on wood

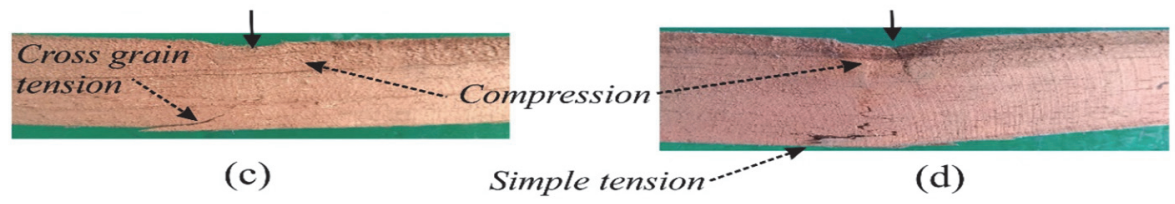

Fig. 10. Failure to bend the malapoga wood using sea water; (a) 2 weeks, (b) 4 weeks, (c) 6 weeks, (d) 8 weeks

Figure 10 shows the failure of malapoga wood due to bending load using sea water immersion. Immersion 2 and 6 weeks looks cracked in the outermost fibers that spread across or across the direction of the fiber or called cross grain tension failure. Whereas for soaking 4 and 8 weeks, cracks occur due to compressive forces on the wood and cracks in the lower parts of the wood that spread in the direction of parallel fibers or failure is called simple tension.

Figure 11 shows malapoga wood failure due to bending load using river water immersion. Wood that has been immersed for 2 weeks has failed in the form of cracks due to compressive force and also has cracks that spread across. Whereas in the immersion 4,6 and 8 weeks the wood appeared to be cracked in a direction parallel to the fibber at the bottom of the wood due to compression or compressive force on the wood.

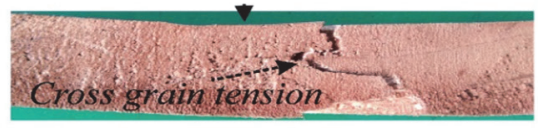

(a)

Compressive force on wood

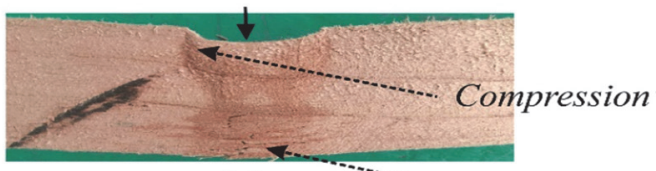

(c)
Simple tension

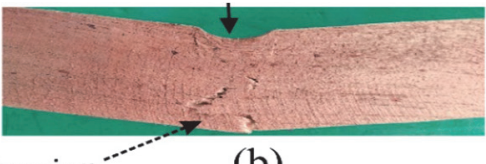

(b)

Compressive force on wood

Figure 11. Failure to bend the malapoga wood using river water; (a) 2 weeks, (b) 4 weeks, (c) 6 weeks, (d) 8 weeks

\section{Conclusion}

Based on data from the results of research that has been done, it can be concluded as follows:

1. Immersion using river water provides greater bending strength value followed by using brackish water and sea water. Maximum bending strength in river water is $26.64 \mathrm{MPa}$ at the time of immersion 4 weeks then followed by brackish water at $25.86 \mathrm{MPa}$ while the maximum bending strength value in seawater occurs in immersion for 6 weeks that is equal to $24.52 \mathrm{MPa}$. 
2. The value of bending strength for brackish water, sea water and river water will increase ie at the time of immersion 2 weeks to 4 weeks and will experience a decrease in bending strength with increasing immersion time of 4 weeks. The immersion time causes the malapoga wood to become denser due to all the cavities in the malapoga wood filled with material contained in brackish water, sea and river so that the fibers of malapoga wood close up, dry out and crystallize inside the malapoga wood cavity which causes the bending strength of malapoga to increase.

\section{References}

1. Pestka, A., Kłosowski, P., Lubowiecka, I., \& Krajewski, M., Influence of Wood Moisture on Strength and Elastic Modulus for Pine and Fir Wood Subjected to 4-point Bending Tests. IOP Conference Series: Materials Science and Engineering, 471, 0-9. (2019)

2. Green, D. W., Winandy, J. E., \& Kretschmann, D. E. Mechanical Properties of Wood Determined. Science, 46, 516-517. (1917)

3. Franke, S., Franke, B., \& Harte, A. M. Failure modes and reinforcement techniques for timber beams-State of the art. Construction and Building Materials, 97, 2-13. (2015)

4. American Society for Testing and Materials. Annual Book of ASTM Standards Volume 04.10 Wood D143, American Society for Testing and Materials. 2008 